\title{
A STUDY ON THE EFFICACY OF INTRATHECAL CLONIDINE AS AN ADJUVANT TO BUPIVACAINE IN POSTOPERATIVE ANALGESIA
}

Narmatha Yangtse Sivanesan'1, Radha Subbiah², Jeyabaskaran Arunachalam D. $A^{3}$

${ }^{1}$ Senior Assistant Professor, Department of Anaesthesiology, Coimbatore Medical College.

${ }^{2}$ Assistant Professor, Department of Anaesthesiology, Coimbatore Medical College.

${ }^{3}$ Associate Professor, Department of Anaesthesiology, Coimbatore Medical College.

\section{ABSTRACT}

\section{BACKGROUND}

Many drugs have been used as adjuvants to bupivacaine intrathecally to prolong the duration of analgesia in the postoperative period. In this study, we evaluate the effects of adding clonidine to bupivacaine intrathecally to prolong the postoperative analgesia.

The aims of this study is to compare the degree and duration of analgesia provided by intrathecal bupivacaine and clonidine with bupivacaine alone.

\section{MATERIALS AND METHODS}

This study was conducted in 40 patients belonging to ASA Grade I and Grade II, aged 20 to 50 years, undergoing lower limb orthopaedic surgeries. After getting Ethical Committee approval, they were divided into two groups of 20 each. Clonidine Group (BC) received $12.5 \mathrm{mg}$ of $0.5 \%$ hyperbaric bupivacaine $+1 \mathrm{mcg} / \mathrm{kg}$ of preservative free clonidine. Control Group (BS) received 12.5 mg of $0.5 \%$ hyperbaric bupivacaine + identical volume of NS. Following data were recorded for 24 hrs. after surgery - Onset and duration of sensory blockade and analgesic duration using VAS pain score and side effects.

\section{RESULTS}

Results showed there is a significant prolongation of sensory block (240 mins) in clonidine group when compared to saline group (130 mins). Similarly, postop analgesia is significantly prolonged in clonidine group (592 mins) when compared to saline group (213 mins).

\section{CONCLUSION}

The addition of clonidine to $0.5 \%$ hyperbaric bupivacaine intrathecally as an adjuvant prolongs the duration of postoperative analgesia.

\section{KEYWORDS}

Intrathecal Block, Clonidine.

HOW TO CITE THIS ARTICLE: Sivanesan NY, Subbiah R, Arunachalam JDA. A study on the efficacy of intrathecal clonidine as an adjuvant to bupivacaine in postoperative analgesia. J. Evolution Med. Dent. Sci. 2017;6(17):1362-1366, DOI: 10.14260/Jemds/2017/296

\section{BACKGROUND}

Local anaesthetics are commonest agents used for spinal anaesthesia. A number of adjuvants have been used intrathecally to prolong the intraoperative and postoperative analgesia. Opioids are commonly used as adjuvants, but side effects such as pruritus, nausea, urinary retention and delayed respiratory depression are unavoidable. So clonidine a selective alpha-2 adrenergic agonist is extensively evaluated as an adjuvant to intrathecal local anaesthetics.

L Nieme et al in his study used $3 \mathrm{mcg} / \mathrm{kg}$ of clonidine to bupivacaine in patients undergoing knee arthroscopy, but hypotension was severe in that dose. So we used $1 \mathrm{mcg} / \mathrm{kg}$ in our study and the results showed prolonged postoperative analgesia without any severe fall in BP.

Financial or Other, Competing Interest: None.

Submission 20-01-2017, Peer Review 14-02-2017,

Acceptance 20-02-2017, Published 27-02-2017.

Corresponding Author:

Dr. Narmatha Yangtse Sivanesan,

Senior Assistant Professor,

Department of Anaesthesiology,

Coimbatore Medical College,

E-mail: yangtsehere@yahoo.co.in

DOI: $10.14260 /$ jemds $/ 2017 / 296$
The aim of the study was to evaluate and compare the degree and duration of analgesia provided by intrathecal bupivacaine and clonidine with bupivacaine alone.

\section{MATERIALS AND METHODS}

40 patients belonging to ASA Grade I and Grade II, aged 20 to 50 years undergoing lower limb orthopaedic surgeries were taken for the study and divided into 2 groups. BC Group ( $n=20)$ Clonidine Group, BS Group $(n=20)$ Control Group.

The study design was a prospective, randomised and double-blind study.

\section{Exclusion Criteria}

- Hypertensives.

- CAHD patients.

- Patients with Spinal deformities.

- Previous Spinal Surgeries.

- Weight $>120$ Kgs.

- Height $<150 \mathrm{~cm}$.

\section{METHODS}

All patients were advised NPO for 6 hrs. before surgery and pre-medicated with Tablet Diazepam $5 \mathrm{mg}$ on the night before surgery. 
All routine investigations were carried out and informed and written consent was obtained. During the pre-anaesthetic visit, patients were familiarised with visual analog scale.

In Operation Theater - Basal Pulse Rate, Blood Pressure and Mean Arterial Pressure were recorded after connecting to monitors (NIBP, ECG, $\mathrm{SpO}_{2}$ ). An 18-G IV line was started and patients were preloaded with $15 \mathrm{~mL} / \mathrm{kg}$ of RL 15 mins. prior to intrathecal drug administration. After the patient was positioned in the left lateral decubitus position and after adequate aseptic precaution lumbar puncture was performed at L3-L4 space by midline approach using 25-G QN.

Patient in the BC Group received $12.5 \mathrm{mg}$ of $0.5 \%$ hyperbaric bupivacaine $+1 \mathrm{mcg} / \mathrm{kg}$ of preservative free clonidine, and patients in BS Group received $12.5 \mathrm{mg}$ of $0.5 \%$ hyperbaric bupivacaine with identical volume of normal saline.

The level of sensory blockade was assessed by pinprick test every 5 mins. in the $1^{\text {st }}$ hour, then hourly for $8 \mathrm{hrs}$. Haemodynamic parameters like heart rate, NIBP (MAP) and SpO2 were recorded every 5 minutes till the end of surgery, then hourly for 8 hours. A fall in BP of $>20 \%$ of baseline was treated with rapid infusion of IV fluids and injection Ephedrine intravenously if necessary. Bradycardia of < $50 / \mathrm{min}$ was treated with Inj. Atropine $0.2 \mathrm{mg}$ intravenously.

In post-anaesthesia room, intensity of pain was assessed using VAS at hourly interval for 24 hours. If VAS $>4$ or moderate pain was treated with rescue analgesia (diclofenac sodium $75 \mathrm{mg}$ IM). Frequency and total dosage of rescue analgesic was recorded in each case. Patients were observed for side effects like nausea, vomiting, shivering and sedation per and postoperatively.

Various data like hear rate, BP (MAP), respiratory rate, $\mathrm{SpO} 2$ and duration of analgesia were recorded and compared with control values using student t-test. ( $\mathrm{P}$ value $<0.05$ was taken significant).

\section{RESULTS}

\begin{tabular}{|c|c|c|}
\hline & $\begin{array}{c}\text { BS Group } \\
\mathbf{N}=\mathbf{2 0}\end{array}$ & $\begin{array}{c}\text { BC Group } \\
\mathbf{N}=\mathbf{2 0}\end{array}$ \\
\hline $\begin{array}{c}\text { Age (yrs.) } \\
\text { Mean } \pm \text { SD }\end{array}$ & $39.75( \pm 4.83)$ & $40.32( \pm 4.38)$ \\
\hline $\begin{array}{c}\text { Weight (kgs) Mean } \\
\pm \text { SD }\end{array}$ & $56.3( \pm 5.31)$ & $57.93( \pm 4.75)$ \\
\hline $\begin{array}{c}\text { Height (cms) } \\
\text { Mean } \pm \text { SD }\end{array}$ & $156.27( \pm 3.07)$ & $155.47( \pm 2.45)$ \\
\hline ASA I & 18 & 19 \\
\hline ASA II & 2 & 1 \\
\hline \multicolumn{2}{|c|}{ Table I. Demographic Characteristics } \\
\hline
\end{tabular}

\begin{tabular}{|c|c|c|}
\hline & $\begin{array}{c}\text { BS Group } \\
\mathbf{N}=\mathbf{2 0}\end{array}$ & $\begin{array}{c}\text { BC Group } \\
\mathbf{N}=20\end{array}$ \\
\hline $\begin{array}{c}\text { Duration of Surgery } \\
\text { Mean (Range) }\end{array}$ & $\begin{array}{c}135 \\
(116-160) \\
\end{array}$ & $\begin{array}{c}137.35 \\
(120-162) \\
\end{array}$ \\
\hline $\begin{array}{c}\text { Regression of Sensory Block } \\
\text { by } 2 \text { Segments (min.) }(\mathrm{P}< \\
0.001)(\mathrm{M} \pm \mathrm{SD})\end{array}$ & $130( \pm 23.16)$ & $240( \pm 34.18)$ \\
\hline $\begin{array}{c}\text { Analgesia Time (min.) } \\
(\mathrm{P}<0.001)(\mathrm{M} \pm \mathrm{SD})\end{array}$ & $213( \pm 25.54)$ & $592( \pm 43.5)$ \\
\hline $\begin{array}{c}\text { No. of Diclofenac Injections } \\
\text { in } 24 \text { Hrs. }(\mathrm{P}<0.05) \text { Mean } \\
\text { (Range) }\end{array}$ & $2.72(2-3)$ & $1.26(1-2)$ \\
\hline
\end{tabular}

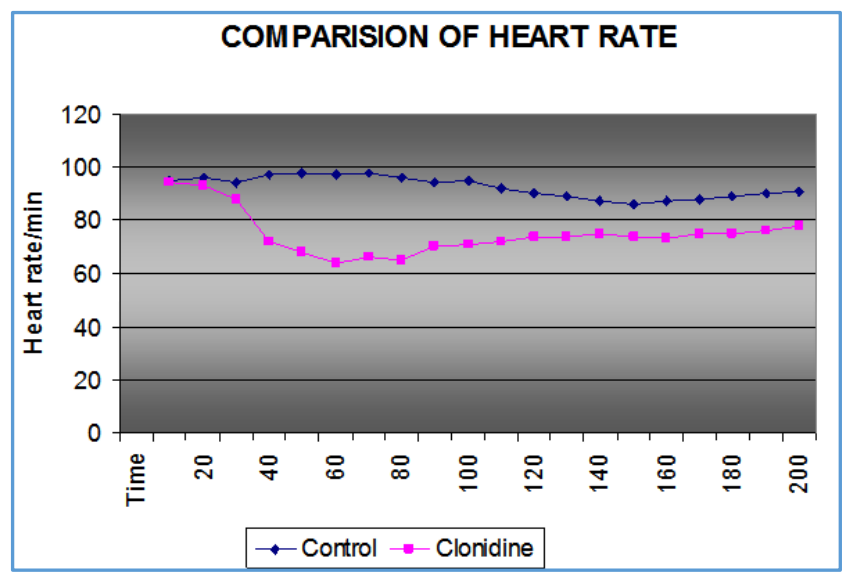

Graph 1

There was a fall in the heart rate in clonidine group, but none of them required any therapeutic intervention.

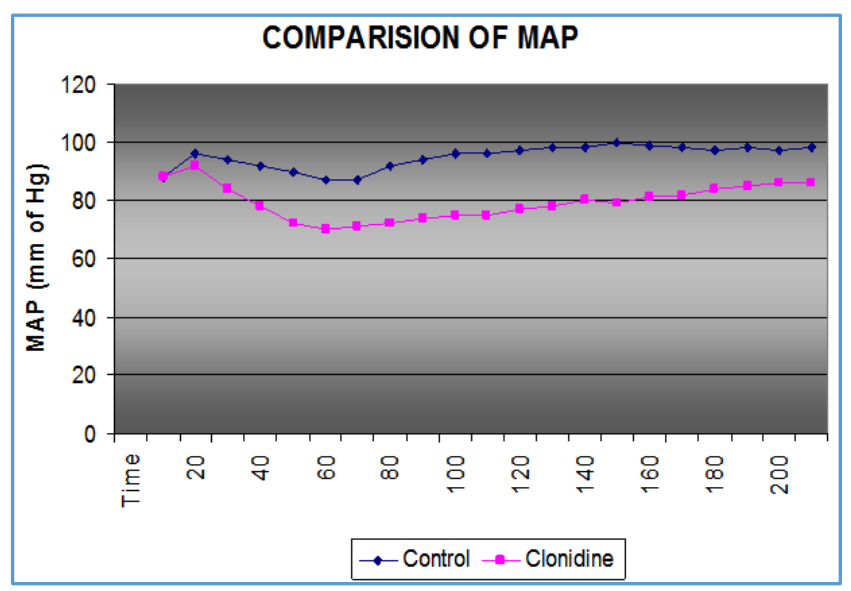

Graph 2

There was a fall in mean arterial pressure in clonidine group without any adverse effects.

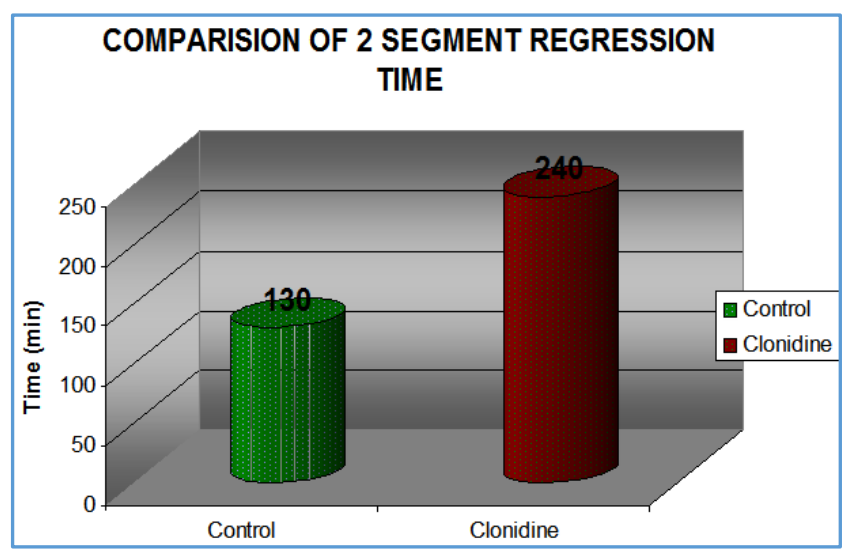

Graph 3

The diagram shows there is a significant difference in 2 segment regression of sensory blockade between the two groups $(\mathrm{P}<0.001)$. 


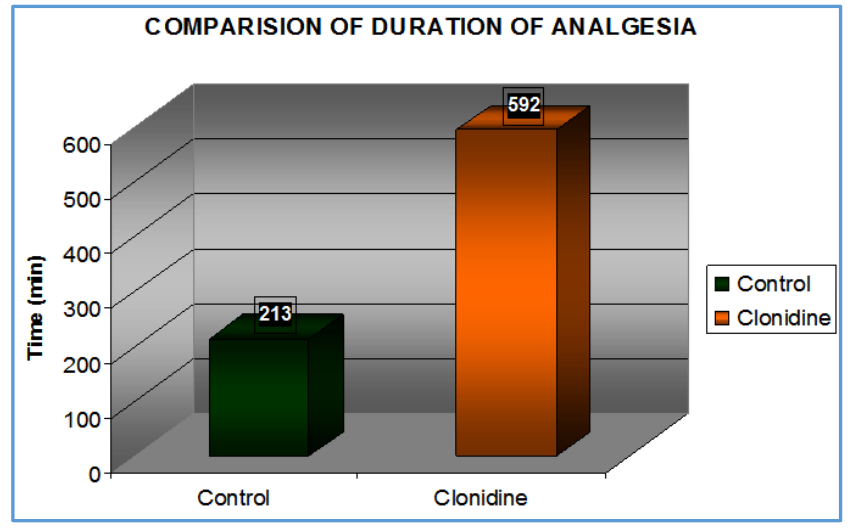

Graph 4

There was a significant prolongation of duration of analgesia in clonidine group $(\mathrm{P}<0.001)$.

\begin{tabular}{|c|c|c|}
\hline & BS Group & BC Group \\
\hline Nausea & 1 & 2 \\
\hline Sedation & 0 & 12 \\
\hline Desaturation & 0 & 0 \\
\hline Shivering & 3 & 0 \\
\hline Respiratory Depression & 0 & 0 \\
\hline \multicolumn{2}{|c|}{ Table III. Side Effects between Groups } \\
\hline
\end{tabular}

\section{DISCUSSION}

Clonidine is a selective partial $\alpha_{2}$-adrenergic agonist with a selectivity ratio of 200:1.

\section{Mechanism of Action of Clonidine}

Intrathecal effect is mediated through the activation of $\alpha_{2}$ receptors in superficial laminae of the spinal cord. $\mathrm{C}$ and $\mathrm{A}_{\delta}$ fibres which are the key elements in nociceptive processing system terminate here. Clonidine acts by blocking the conductance of $\mathrm{C}$ and $\mathrm{A} \delta$ fibres by inhibiting the voltage gated $\mathrm{Na}^{+}$and $\mathrm{K}^{+}$channels and suppresses the generation of action potential in the tonic-firing spinal dorsal horn neurons.

Some contribution is derived from release of acetylcholine from neuraxial region and by inhibition of substance - $\mathrm{P}$ release.

L Neimi et al $^{1}$ in their study of patients undergoing knee arthroscopy used $3 \mathrm{mcg} / \mathrm{kg}$ of clonidine to $15 \mathrm{mg}$ of bupivacaine intrathecally to achieve postop analgesia. The mean duration of postop analgesia achieved in their study (603 mins.) was comparable with ours (592 mins.).

Patients in L Neimi et al group had significant fall in MAP and heart rate, which required interventions while using 3 $\mathrm{mcg} / \mathrm{kg}$ of clonidine intrathecally. Even though there was significant fall in MAP and heart rate in the clonidine group in our study, none required any therapeutic interventions.

Fogarty D J et $\mathrm{al}^{2}$ studied the anaesthetic and analgesic properties of intrathecal clonidine and intrathecal morphine in patients undergoing total hip replacement under spinal anaesthesia, which showed both intrathecal clonidine and intrathecal morphine prolonged the time to first analgesia compared with saline (mean 278 (SD 93.2) mins., 498 (282.4) mins. and 54 (61.9) mins., respectively) ( $<<0.001)$. Intrathecal clonidine prolonged the duration of spinal analgesia, but was markedly inferior to the intrathecal morphine in providing subsequent postoperative analgesia.
Our study showed the effect of clonidine in prolonging the duration of postop analgesia than control group, which was similar to the effect achieved by Fogarty et al.

Dobrydnjov et $\mathrm{al}^{3}$ in their study compared intrathecal clonidine with oral clonidine $(150 \mathrm{mcg})$ for postop pain relief in orthopaedic patients and found that intrathecal clonidine prolonged analgesia and decreased morphine usage postoperatively than oral clonidine, which was in coherence with our study results and also hypotension was less pronounced in intrathecal group than oral clonidine group.

Data obtained in our study by addition of $1 \mathrm{mcg} / \mathrm{kg}$ of clonidine (max. dose used in our study $75 \mathrm{mcg}$ ) to bupivacaine significantly prolongs the duration of postop analgesia and also reduces the need for postop analgesic requirement.

Eisenach $\mathrm{JC}^{4}$ in his study showed $30 \mathrm{mcg}$ clonidine was associated with more incidence and duration of hypotension than $15 \mu \mathrm{g}$ of clonidine; $15 \mathrm{mcg}$ clonidine added to $11 \mathrm{mg}$ hyperbaric bupivacaine provides better sensory and motor blockade for inguinal herniorrhaphy.

On comparing with our study, there was a significant fall in MAP in clonidine group without any significant adverse effects.

Similarly, Chiari et al ${ }^{5}$ in dose response study of intrathecal clonidine as a sole agent in 1 st stage of labour in dose of (50 - $200 \mathrm{mcg}$ ) had quality of analgesia more pronounced in higher doses than $50 \mathrm{mcg}$. But higher doses had deleterious effects both in mother and foetus, which renders support the analgesic effect in our study.

De Negri $\mathrm{P}$ et $\mathrm{al}^{6}$ showed that the addition of clonidine to hyperbaric bupivacaine seems to be particularly useful in unilateral spinal anaesthesia, exerting minimal influence on haemodynamic parameters and guaranteeing a satisfactory postoperative analgesia, which was incoherence with the results achieved in our study.

Reddy SVR, Yaksh TL et al7 in his study using 25 mcg of clonidine along with $7.5 \mathrm{mg}$ of bupivacaine intrathecally showed improvement in the duration and quality of spinal anaesthesia; it also provides longer duration of postoperative analgesia without significant side effects. The results achieved in our study showed prolongation of postop analgesia, which is similar to his study.

Filos $\mathrm{K} \mathrm{S}$ et al 8 in their results demonstrate dosedependent analgesia after intrathecal clonidine at doses as great as 450 micrograms. The nearly immediate analgesic effect observed after intrathecal injection of 300 and 450 micrograms clonidine strongly argues for a spinal rather than a systemic site of action of this alpha- 2 adrenergic agonist, which renders the support to our result in the effect of clonidine on spinal action even in higher doses without significant effect on systemic action.

B S Sethi et al ${ }^{9}$ in their study of low-dose intrathecal clonidine on postop analgesia showed postop analgesia time of 612 mins. and analgesic requirement of less than 2 injections in 24 hrs., which was similar to the results obtained in our study.

Evidence of intrathecal clonidine in increasing the duration of analgesia was supported by Strebel S10 et al. In their dose response study on small-dose intrathecal clonidine and isobaric bupivacaine for orthopaedic surgery showing duration of the sensory block (regression below level L1) was increased in patients receiving intrathecal clonidine: $288+$ - 
62 mins. (Group 1, control), $311+/-101$ mins. in Group 2 (+8\%), $325+/-69$ mins. in Group $3(+13 \%)$ and $337+/-78$ mins. in Group $4(+17 \%)$ (estimated parameter for dose 0.23 , also duration of pain relief from intrathecal clonidine administration until the first request for supplemental analgesia was significantly prolonged without significant alteration in haemodynamic stability and sedation score.

In Clinical Anaesthesia by Barash et al, $5^{\text {th }}$ edition, chapter 12 discussed that addition of $75 \mathrm{mcg}$ to $150 \mathrm{mcg}$ of clonidine to subarachnoid tetracaine or bupivacaine prolonged the duration of sensory and motor blockade indicating the analgesic effect given of clonidine in our study.

Millers et al in text book of anaesthesia, $6^{\text {th }}$ edi, vol. 1 , chapter 16, P 650 - 51 - alpha adrenergic agonists said that addition of clonidine to epidural or intrathecal drugs prolongs the duration of sensory and motor blockade supporting our study.

Acalovschi I, Bodolea $\mathrm{C}$ et al ${ }^{11}$ in their study on the effects of added alpha adrenergic agonists to spinal anaesthesia with Meperidine showed that the addition of clonidine prolonged the postoperative analgesia $(\mathrm{P}<0.001)$, but was associated with an increased sedation score. The incidence of other side effects did not differ between the groups. They concluded that coadministration of epinephrine or clonidine with meperidine enhances the duration and degree of spinal anaesthesia and that adding clonidine prolongs the duration of postoperative analgesia, which renders support to our study in the effect on postoperative analgesia.

De Kock et $\mathrm{al}^{12}$ in their study for analgesia for ambulatory knee surgery proved that addition of small doses of clonidine to ropivacaine in spinal anaesthesia has given adequate analgesia for knee surgeries once again lending support to the analgesic effect of clonidine in our study.

Van Tuijl I, Giezeman MJ et al ${ }^{13}$ showed the combination of intrathecal low-dose hyperbaric bupivacaine-clonidine in knee arthroscopy showed clonidine group patients had better analgesic effect, which adds support to the analgesic effect of clonidine shown in our study group.

Van Tuijl I, Van Klei WA et $\mathrm{al}^{14}$ in their study on addition of intrathecal clonidine to hyperbaric bupivacaine on postoperative pain after caesarean section showed that the addition of clonidine $(75 \mathrm{mcg})$ to hyperbaric bupivacaine prolongs spinal anaesthesia after caesarean section and improves early analgesia, but does not reduce the postoperative morphine consumption during the first $24 \mathrm{hrs}$. showing low-dose clonidine improves analgesia without any side effects as our study.

Shetty PS, et al ${ }^{15}$ showed addition of 30 mcg clonidine to intrathecal hyperbaric bupivacaine was associated with more incidence and duration of hypotension than $15 \mu \mathrm{g}$ of clonidine; $15 \mathrm{mcg}$ clonidine added to $11 \mathrm{mg}$ hyperbaric bupivacaine provides better sensory and motor blockade for inguinal herniorrhaphy rendering support to our study that clonidine analgesic effect.

\section{CONCLUSION}

Addition of clonidine $1 \mathrm{mcg} / \mathrm{kg}$ to $0.5 \%$ hyperbaric bupivacaine intrathecally significantly increases -

1. Duration of analgesia when compared to $0.5 \%$ hyperbaric bupivacaine alone.

2. This dose does have effect on mean arterial pressure, heart rate and sedation; however, no therapeutic interventions were needed for it.
Inferring that addition of $1 \mathrm{mcg} / \mathrm{kg}$ of clonidine to intrathecal bupivacaine is safe in achieving a good postoperative analgesia with less side effects.

\section{REFERENCES}

[1] Niemi L. Effects of intrathecal clonidine on duration of bupivacaine spinal anaesthesia, haemodynamics and postoperative analgesia in patients undergoing knee arthroscopy. Acta Anaesthesiol Scand 1994;38(7):7248.

[2] Fogarty DJ, Carabine UA, Milligan KR. Comparision of the analgesic effects of intrathecal clonidine and intrathecal morphine after spinal anaesthesia in patients undergoing total hip replacement. $\mathrm{Br} \mathrm{J}$ Anaesth 1993;71(5):661-4.

[3] Dobrydnjov I, Axelsson K, Thorn SE, et al. Clonidine combined with small-dose bupivacaine during spinal anaesthesia for inguinal herniorrhaphy: a randomized double-blinded study. Anaesth Analg 2003;96(5):1496-503.

[4] Eisenach JC. Overview: First international symposium on alpha-2 adrenergic mechanisms of spinal anaesthesia. Reg Anaesth 1993;18(4):207-12.

[5] Chiari A, Eisenach JC. Spinal anaesthesia: mechanisms, agents, methods and safety. Reg Anesth Pain Med 1998;23(4):357-62.

[6] De Negri P, Borelli F, Salvatore R, et al. Spinal anaesthesia with clonidine and bupivacaine in young humans: interactions and effects on cardiovascular system. Minerva Anesthesiology 1997;63(4):119-25.

[7] Reddy SV, Yaksh TL. Spinal noradrenergic terminal system mediates antinociception. Brain Res 1980;189(2):391-401.

[8] Filos KS, Goudas LC, Patroni 0, et al. Intrathecal clonidine as a sole analgesic for pain releif after caesarean section. Anaesthesiology 1992;77(2):26774.

[9] Sethi BS, Samuel M, Sreevastava D, et al. Efficacy of analgesic effects of low dose intrathecal clonidine as an adjuvant to bupivivaine. Indian Journal of Anesthesia 2007;51(5):415-19.

[10] Strebel S, Gurzeler JA, Schneider MC, et al. Small-dose intrathecal clonidine and isobaric bupivacaine for orthopaedic surgery: a dose response study. Anesth Analg 2004;99(4):1231-8.

[11] Acalovschi I, Bodolea C, Manoiu C. Spinal anaesthesia with meperidine. Effects of added $\alpha$ adrenergic agonists: epinephrine vs clonidine. Anesth Analg 1997;84(6):1333-9.

[12] De Kock M, Gautier P, Fanard L, et al. Intrathecal ropivacaine and clonidine for ambulatory knee arthroscopy: a dose-response study. Anesthesiology 2001;94(4):574-8.

[13] van Tuijl I, Giezeman MJ, Braithwaite SA, et al. Intrathecal low dose hyperbaric bupivacaineclonidine combination in outpatient knee arthroscopy: a randomized controlled trial. Acta Anaesthesiol Scand 2008;52(3):343-9. 


\section{Jemds.com}

[14] van Tuijl I, van Klei WA, van der Werff DB, et al. The effect of addition of intrathecal clonidine to hyperbaric bupivacaine on postoperative pain and morphine requirements after Caesarean section: a randomized controlled trial. Br J Anaesth 2006;97(3):365-70.

\section{Original Research Article}

[15] Shetty PS, Picard J. Adjuvant agents in regional anaesthesia. Anaesth Intensive Care Med 2006;7(11):407-10. 